\title{
Innovative Autostatic Laryngeal Stent Used in the Treatment of Laryngeal Stenosis
}

\author{
RAZVAN HAINAROSIE ${ }^{1,2}$, IRINA GABRIELA IONITA ${ }^{1 *}$, MURA HAINAROSIE ${ }^{1}$, CATALINA PIETROSANU', \\ DRAGOS CRISTIAN STEFANESCU ${ }^{3}$, VIOREL ZAINEA ${ }^{1,2}$ \\ ${ }^{1}$ University of Medicine and Pharmacy Carol Davila Bucharest, 37 Dionisie lupu Str., 020021, Bucharest, Romania \\ ${ }^{2}$ Institute of Phonoaudiology and Functional ENT Surgery Prof. Dr. Dorin Hociota, 21 Mihail Cioranu Str., 061344, Bucharest, \\ Romania \\ ${ }^{3}$ Gen. Dr. Aviator Anastasiu Institute of Aeronautical and Spatial Medicine, 88 Mircea Vulcanescu Str., 010825, Bucharest, Romania
}

\begin{abstract}
Laryngeal stenosis represents a serious and challenging condition in the field of otorhinolaryngology. The managementoflaryngeal stenosis is performed in multiple stages, and numerous surgeries can be necessary to obtain a favorable outcome. We present a specially designed laryngeal stent suitable for patients with stenosis of the larynx, that can be used after $\mathrm{CO} 2$ laser resection. The particular shape of the device, the biocompatible material and the autostatic propriety are some important characteristics that improve the tolerability of patients to the stent. The device has multiple advantages that make it a proper therapy method for selected patients with stenosis of the larynx.
\end{abstract}

Keywords: laryngeal stent, stenosis

Laryngeal stenosis represents a serious and one of the most challenging conditions in otorhinolaryngology. The stenosis represents the narrowing of one or more regions of the larynx.

Laryngeal stenosis can be congenital or acquired.

Congenital stenosis appears when the laryngeal tube fails to permeabilize in the 10th week of embryogenesis. Abnormal permeabilization will result in a varying degree of laryngeal stenosis. Congenital webs are located in $70 \%$ of the cases at the glottis area, and they represent almost $5 \%$ of all laryngeal malformations.

The etiology of the acquired laryngeal stenosis is represented by trauma, infection, high-level tracheostomy, prolonged airway instrumentation and autoimmune disorders [1].

If a patient is intubated orally for long periods ( $>10$ days), more than $90 \%$ of the patients will develop some degree of laryngeal stenosis.

Laryngeal trauma is one of the most frequent causes of laryngeal stenosis. In severe cases, the entire larynx and part of the trachea can be affected.

The preoperative assessment of the laryngeal stenosis is done endoscopically and using a CT scan. The endoscopic examination will determine the degree of stenosis, and the imagery will determine the length of the stenosis.

The stenosis length will dictate the treatment of choice, up to $1 \mathrm{~cm}$ the patient is a candidate for the endoscopic procedure. If the stenosis is more than $2 \mathrm{~cm}$, the patient is a candidate for an external approach.

\section{Experimental part}

We propose for the patients with glottis and subglottic stenosis in length of $1 \mathrm{~cm}$ the endoscopic $\mathrm{CO}_{2}$ LASER treatment to permeabilize the stenotic region. The treatment consists in resection of the stenosis using the Shapshay or keyhole technique, followed by mounting a laryngeal stent.

For the first time in 1965, the tracheal stenting was described by Montgomery. A silicone prosthesis was proposed for the tracheal stenting. Endoscopic approach of the stenosis with laryngeal stent placement is a valuable method for the treatment of stenosis of the larynx, and usually tracheotomy is not required [2-5].

The most used stents nowadays are the Montgomery stent and the Montgomery T-tube stent with caps.

Besides the Montgomery T-tube stent, other stents can be used for preventing re-stenosis of the larynx like silastic sheet stents [6].

We propose a new designed auto static laryngeal stent to be used in laryngeal stenosis following $\mathrm{CO}_{2}$ LASER resection of the stenotic lesion. The stent will have a triangular shape resembling the glottis plan in the upper part of the stent. The distal part of the sent will have a round shape. The walls of the stent will have an elastic metallic net that will optimize the auto static properties of the silicone stent. The metallic net is disposed horinzontaly and the height of the stent can be adjust according to the patient needs.

When mounting it the surgeon can deform the stent to insert it into the larynx. After positioning, the stent will take its original shape due to the metallic net within the walls.

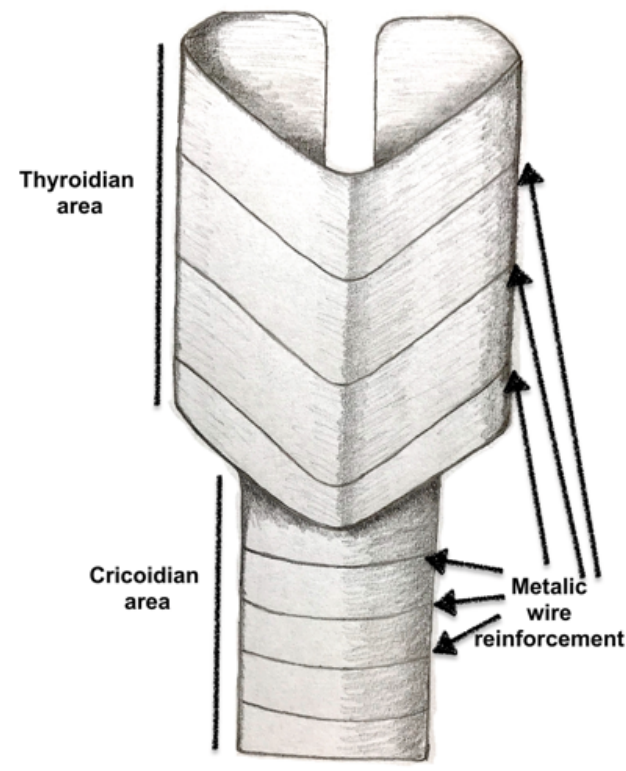

Fig 1. Autostatic laryngeal stent 
At the distal end, the stent will have a particular $U$ shape so that, in case of slipping from the larynx into the tracheal area, the stent will remain inserted into the internal ridge (carina) of the trachea, allowing breathing.

At the distal end the stent will be perforated as a net. If the stent will go down to the trachea due to the perforations the patient will be able to breath.

The material of choice will be a medical grade silicone because it is well tolerated and is tested for biocompatibility.

We selected Polydimethylsiloxane (PDMS) from the group of polymeric organosilicon. PDMS is the most used organic silicone-based polymer. It is clear from the optical point of view, inert and nontoxic. It is also nonflammable.

The chemical formula of the Polydimethylsiloxane (PDMS) is $\mathrm{CH}_{3}\left[\mathrm{Si}\left(\mathrm{CH}_{3}\right)_{2} \mathrm{O}\right] \mathrm{nSi}\left(\mathrm{CH}_{3}\right)_{3}$. Where $\mathrm{N}$ represents how many $\left[\mathrm{SiO}\left(\mathrm{CH}_{3}\right)_{2}\right]$ monomers are repeated (fig.2).

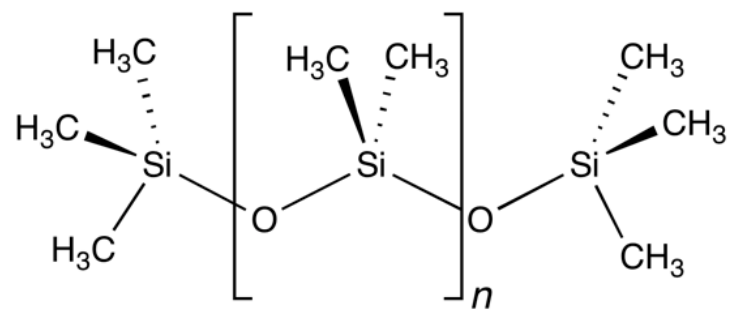

Fig.2. Chemical formula of the Polydimethylsiloxane (PDMS)

The industrial process for the synthesis of the polymer will use dimethyldichlorosilane and water, taking advantage of a polymerization chemical reaction that will produce hydrochloric acid. For medical application, the chlorine groups formed by acetate replaced atoms in the silane precursor are suitable. In that manner, the chemical reaction produces acetic acid. The acetic acid is less aggressive and polluting than the hydrochloric acid. When acetic acid is produced the curing process is much slower.

The process of hydrolysis will generate a polymer $\left(\mathrm{Si}\left(\mathrm{CH}_{3}\right)_{2} \mathrm{Cl}_{2}\right)$ terminated with silanol groups $\left.\left(-\mathrm{Si}\left(\mathrm{CH}_{3}\right)_{2} \mathrm{OH}\right]\right)$.

Usuatly, methyltrichlorosilane is used to produce branches or cross-links in the polymer chains.

PDMS is a flexible polymer molecule that will result in devices with a high level of viscoelasticity

The stent will be placed after $\mathrm{CO}_{2}$ LASER resection of the stenosis. The stent will be inserted through the laryngoscopy tube into the larynx. The length of the stent will be adjusted to the patient anatomy. The elastic metallic net from the stent walls will provide the attachment to the laryngeal walls.

A specific problem is represented by patients that develop stenosis for laryngeal or pharyngolaryngeal tumrs. In such cases, the complexity of the tumor will determine significant locoregional changes in the anatomy $[7,8]$. The intervention, if performed using the $\mathrm{CO}_{2}$ laser, may be extensive, affecting the anterior commissure. In such cases a certain degree of stenosis may occur during the healing process. Although the difficult management of such patients is difficult, due to the multiple possibilities of evolution dictated by the tumor characteristic [9], a minimally invasive procedure may have good results and allow us to continue the healing process by restoring a permeable air way. Also, under advantage of this tube is that it should allow for systemic and local treatment under the supervision of bot oncologist and ENT surgeon, these being means of therapy that have proved their efficacy [10].
After the healing process is complete the stent can be removed using direct laryngoscopy under general anesthesia.

\section{Results and discussions}

We consider the newly designed stent to be useful in the treatment of the laryngeal stenosis. It can be used after the CO2 LASER resection of the lesion.

The specific aspect of the laryngeal stent, with its triangular shape in the upper part, and round shape in the distal part, is perfectly adapted to the anatomy of the larynx. This can enhance the patients' tolerance for the device.

The autostatic design will permit the stent to stay in position without sutures. This particular design has the advantage of being more easily accepted by the patient, improving the quality of life during its usage.

The metallic net will allow the stent to remain attached to the laryngeal wall contributing to the safety characteristics of the device.

Due to it is made of medical grade silicone, it is well tolerated by the tissue, will prevent the scar formation and can be adjusted to the desired length, according to the patient anatomy.

The stent can be removed transorally under general anesthesia using a forceps. The discard maneuvers can be performed quickly, and the duration of the intervention is short. Thus the patient spends little time under general anesthesia

We consider the use of the imagined stent to be safe because in case of sliding into the trachea the stent will remain in the tracheal carina, the patient being able to breathe correctly, and the stent can be removed transorally. The safety of the device is an important advantage for both the patient, and the surgeon.

\section{Conclusions}

This newly designed stent is a valuable option for the treatment of laryngeal stenosis. It is easy to mount, safe to bear, quick to remove. We consider that its' advantages can enhance the adhesion of the patient to the treatment, and can improve the long-term outcomes in the management of laryngeal stenosis in carefully selected patients.

\section{References}

1.PARIDA PK, GUPTA AK. Indian J Otolaryngol Head Neck Surg. 2009, 61, nr. 4, p. 306-12.

2.EDWARDS J, TANNA N, BIELAMOW ICZ SA. Ann Otol Rhinol Laryngol. 2007, 116, nr. 3, p. 211-6.

3.PANIELLO RC, DESAI SC, ALLEN CT, KHOSLA SM. Ann Otol Rhinol Laryngol. 2013, 122, nr. 11, p. 672-8.

4.LIYANAGE SH, KHEMANI S, LLOYD S, FARRELL R. J Laryngol Otol. 2006, 120, nr. 4, p. 322-4.

5.VAAMONDE LAGO P, GARCIA SOTO N, MARTIN MARTIN C, CAJADE FRIAS J M, LABELLA CABALLERO T. An Otorrinolaringol Ibero Am. 2003, 30, nr. 1, p. 39-46.

6.XU W, HAN D, HU H, CHEN X, LI H, HOU L, ZHANG L. Head Neck. 2009, 31, nr. 6, p. 732-7.

7.BERTESTEANU SVG, POPESCU CR, GRIGORE R et. al. Chirurgia, 107, nr. 1, 2012, p. 33-38.

8.POPESCU B, POPESCU CR, GRIGORE R et. al. Romanian Journal of Morphology and Embriology, 53, nr. 2, 2012, p. 243-248.

9.STANCIU AE, ANTON A, ZAMFIR C, STANCIU MM. Romanian biotechnological letters, 22, nr. 2, 2017, p. 12419-26

10.YIPEL M., GHICA M., ALBU M.G. et al. Current Organic Chemistry, 20, nr. 28, 2016, p. 2934-2948 